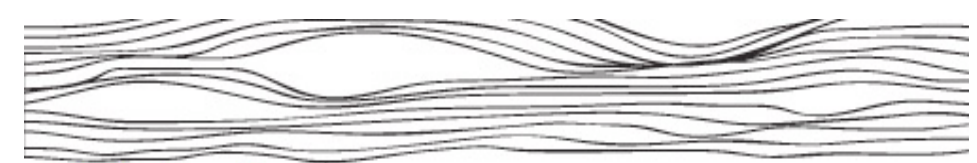

Public Space: The Journal of Law and Social Justice

\title{
THE CRITICAL CRIMINOLOGY COMPANION
}

\section{Editors: Thalia Anthony and Chris Cunneen \\ Hawkins Press 2008}

The Critical Criminology Companion is a wonderful new addition to the field of criminology. The book showcases many of the major Australian and New Zealand politically committed and theoretically sophisticated criminologists writing in their particular area of expertise.

Critical criminology includes a broad range of ideas and concepts which tend to be associated with an oppositional position to much of mainstream criminology and contemporary policy developments. Critical criminology is an intellectual partner of leftwing approaches, but is also associated with feminist, Marxist, racialised analyses of the structural and institutional contexts for crime.

For a while, left-wing criminology appeared to have little of relevance to contribute to policies on crime, due to a failure to adequately respond to economic rationalism and a tendency by left-wing politicians to rely upon law and order politics. The Critical Criminology Companion provides resounding examples of the significance of left-wing approaches to crime, particularly in the chapters on state crime, refugees and torture. 
These chapters provide a framework in which the actions of governments can be meaningfully analysed and judged.

The examples of critical theory in action are timely and thought provoking. Thomsen's chapter on masculinities presents the broad range of theory to date, balanced by Carrington's musings on feminist criminologies. Students loved the chapters on prison and policing, particularly as they successfully integrated criminological theory with practice. Young's musings about why we enjoy crime as entertainment provide insight into the popular cultural images of crime.

The Critical Criminology Companion is probably not suitable as an introductory text for undergraduate criminology. The text assumes a fair amount of knowledge and understanding of criminological theories. However, advanced students in the subject loved to refer to the text to criticise mainstream theories about crime. The text generated much thought and discussion in class, particularly as each paper expressed carefully considered arguments. Readers might not always agree with the ideas of the authors, but each chapter provided a sufficient overview of available research and reasons for ideas, that discussions about ideas were informed and challenged mainstream ways of thinking.

I would highly recommend The Critical Criminology Companion to anyone interested in sophisticated, thought provoking analyses of crime. Readers might initially focus on their specific areas of interest, but will find themselves enticed to consider other chapters. They won't be disappointed. 